07-024

\title{
Managing Functional \\ Biases in Organizational \\ Forecasts: A Case Study of \\ Consensus Forecasting in Supply Chain Planning
}

Rogelio Oliva

Noel Watson 


\title{
Managing Functional Biases in Organizational Forecasts: A Case Study of Consensus Forecasting in Supply Chain Planning
}

\author{
Rogelio Oliva \\ Mays Business School \\ Texas A\&M University \\ College Station, TX 77843-4217 \\ Ph 979-862-3744 | Fx 979-845-5653 \\ roliva@tamu.edu \\ Noel Watson \\ Harvard Business School \\ Soldiers Field Rd. \\ Boston, MA 02163 \\ Ph 617-495-6614 | Fx 617-496-4059 \\ nwatson@hbs.edu
}

Draft: December 14, 2007.

Do not quote or cite without permission from the authors. 


\section{Managing Functional Biases in Organizational Forecasts: A Case Study of Consensus Forecasting in Supply Chain Planning}

\section{Abstract}

To date, little research has been done on managing the organizational and political dimensions of generating and improving forecasts in corporate settings. We examine the implementation of a supply chain planning process at a consumer electronics company, concentrating on the forecasting approach around which the process revolves. Our analysis focuses on the forecasting process and how it mediates and accommodates the functional biases that can impair the forecast accuracy. We categorize the sources of functional bias into intentional, driven by misalignment of incentives and the disposition of power within the organization, and unintentional, resulting from informational and procedural blind spots. We show that the forecasting process, together with the supporting mechanisms of information exchange and elicitation of assumptions, is capable of managing the potential political conflict and the informational and procedural shortcomings. We also show that the creation of an independent group responsible for managing the forecasting process, an approach that we distinguish from generating forecasts directly, can stabilize the political dimension sufficiently to enable process improvement to be steered. Finally, we find that while a coordination system — the relevant processes, roles and responsibilities, and structure—can be designed to address existing individual and functional biases in the organization, the new coordination system will in turn generate new individual and functional biases. The introduced framework of functional biases (whether those biases are intentional or not), the analysis of the political dimension of the forecasting process, and the idea of a coordination system are new constructs to better understand the interface between operations management and other functions.

Keywords: forecasting, marketing/operations interface, sales and operations planning, organizational issues, caselfield study. 


\section{Introduction}

The importance of forecasting for operations management cannot be overstated. Within the firm, forecast generation and sharing is used by managers to guide the distribution of resources (Antle and Eppen, 1985; Stein, 1997), to provide targets for organizational efforts (Hamel and Prahalad, 1989; Keating et al., 1999), and to integrate the operations management function with the marketing (Crittenden et al., 1993; Griffin and Hauser, 1992), sales (Lapide, 2005; Mentzer and Bienstock, 1998), and product development (Griffin and Hauser, 1996; Wheelwright and Clark, 1992) functions. Errors in forecasting often cross the organizational boundary and translate into misallocation of resources that can impact shareholders' return on investment (Copeland et al., 1994), and affect customers' perception of service quality (Oliva, 2001; Oliva and Sterman, 2001). Across the supply chain, forecast sharing is a prevalent practice for proactively aligning capacity and managing supply (Cachon and Lariviere, 2001; Terwiesch et al., 2005).

Over the past five years, demand/supply planning processes for planning horizons in the intermediate range have been receiving increasing attention, especially as the information technology originally intended to facilitate this planning has achieved limited success. Crossfunctional coordination among groups such as sales, operations, and finance is needed to ensure the effectiveness of some of these planning processes and the forecasting that supports it. Such processes have been referred to in the managerial literature as sales and operations planning (S\&OP) processes (Bower, 2005; Lapide, 2005). Forecasts within this multi-functional setting that characterizes many organizations cannot be operationalized or analyzed in an organizational and political vacuum. However, to date, little research has been done on managing the organizational and political dimensions of generating and improving forecasts in corporate settings; dimensions which determine significantly the overall effectiveness of the forecasting process (Bretschneider and Gorr, 1989, p. 305). 
We present a case study that illustrates the implementation of an S\&OP process, concentrating in detail on the forecasting approach around which the planning process revolves. Our study describes how individuals and functional areas (whether intentionally or not) biased the organizational forecast and how the forecasting process implemented managed those biases in a supply chain setting that requires responsive planning. We define biases broadly here to include those occasioned by functional and individual incentives, and informational or procedural shortcomings. Our analysis reveals that the forecasting process, together with the supporting mechanisms of information exchange and elicitation of assumptions, is capable of managing the political conflict and the informational and procedural shortcomings that accrue to organizational differentiation. We show that the creation of an independent group responsible for managing the forecasting process can stabilize the political dimension sufficiently to enable process improvement to be steered. The deployment of a new system, however, introduces entirely new dynamics in terms of influence over forecasts and active biases. The recognition that the system both needs to account, and is in part responsible, for partners' biases introduces a level of design complexity not currently acknowledged in the literature or by practitioners.

The rest of this paper is structured as follows: In section 2, we review the relevant forecasting literature motivating the need for our case study and articulating hypotheses for findings in our research setting. Our research site and methodological design are described in section 3 . In section 4 we report the conditions that triggered the deployment of the forecasting process, assess its impact in the organization, and describe the process, its actors, and dynamics in detail. Section 5 contains the core of our analysis: we analyze the organizational and process changes that were deployed, and assess how intentional and unintentional biases in the organization were managed through these mechanisms. Some of the challenges the organization faces under the new forecasting process are explored in section 6 , which also provides a framework for understanding the need to continuously 
monitor and adapt to the processes. The paper concludes with an evaluation of the implications of our findings for practitioners and researchers.

\section{Research Motivation}

Most organizations use forecasts as input to comprehensive planning processes-such as financial planning, budgeting, sales planning, and finished goods inventory planning - that are charged with accomplishing particular goals. This implies that the forecast needs not only to be accepted by external parties, but also to guide efforts of the organization. Thus, an important measure of forecast effectiveness is how much they support these planning needs. The fit between forecasting and planning is an under-studied relationship in the literature, but at a minimum level, the forecast process needs to match the planning process in terms of the frequency and speed in which the forecast is produced. The forecasting horizon and accuracy of the forecast should be such that it allows the elaboration and execution of plans to take advantage of the forecast (Makridakis et al., 1998; Mentzer and Bienstock, 1998). For example, a planning approach such as Quick Response (Hammond, 1990) requires as input a sense of the uncertainty surrounding the forecasts in order to manage production. Thus, the forecasting process complementing such a planning process should have a means of providing a relative measure of uncertainty (Fisher et al., 1994; Fisher and Raman, 1996).

Nevertheless, forecasting is not an exact science. In an organizational setting, the forecasting process requires information from multiple sources (e.g., intelligence about competitors, marketing plans, channel inventory positions, etc.) and in a variety of formats, not always amenable to integration and manipulation (Armstrong, 2001b; Fildes and Hastings, 1994; Lawrence et al., 1986; Makridakis et al., 1998). Existing case studies in the electronic and financial industries (e.g., Hughes, 2001; Watson, 1996) emphasize the informational deficiency in creating organization forecasts as a result of poor communication across functions. The multiplicity of data sources and 
formats creates two major challenges for a forecasting process. First, since not all information can be accurately reflected in a statistical algorithm, judgment calls are a regular part of forecasting processes (Armstrong, 2001a; Sanders and Manrodt, 1994; Sanders and Ritzman, 2001). The judgmental criteria to make, adjust, and evaluate forecasts can result in individual and functional limitations and biases that potentially compromise the quality of the forecasts. Second, since the vast majority of the information providers and the makers of those judgment calls are also the users of the forecast, there are strong political forces at work explicitly attempting to bias the outcome of the process.

Thus the forecasting process, in addition to fitting with the organization planning requirements, needs to explicitly manage the biases (whether individual or functional) that might affect the outcome of the process. We recognize two potential sources of biases in the organization intentional and unintentional - that incorporate the judgmental, informational, and political dynamics that affect forecasting performance. In the following subsections, we provide analytical context from relevant literature to articulate frameworks and expectations that will help the reader to assimilate the case details in these two dimensions.

\subsection{Managing Biases due to Incentive Misalignment and Dispositions of Power}

Intentional sources of bias (i.e., an inherent interest and ability to maintain a level of misinformation in the forecasts) are created by incentive misalignment across functions coupled with a particular disposition of power within the organization. Local incentives will drive different functional groups to want to influence the forecast process in directions that might benefit their own agenda. For example, a sales department — compensated through sales commissions — might push to inflate the forecast to ensure ample product availability, while the operations group — responsible for managing suppliers, operating capacity, and inventories — might be interested in a forecast that smoothes demand and eliminate costly production swings (Shapiro, 1977). Power is the ability of 
the functional group to influence the forecast, and is normally gained by access to a resource (e.g., skill, information) that is scarce and valued as critical by the organization, and the ability to leverage such resources is contingent to the degree of uncertainty surrounding the organizational decision-making process (Salancik and Pfeffer, 1977). For example, the power that a sales organization could extract from intimate knowledge of customer demand diminishes as that demand becomes stable and predictable to the rest of the organization. Mahmoud et al. (1992) in discussing the gap between forecasting theory and practice, refers in particular to the effects of the disparate functional agendas and incentives as the political gap, while according to Hanke and Reitsch (1995) the most common source of bias in a forecasting context is political pressure within a company. Thus, forecasts within a multi-functional setting cannot be operationalized or analyzed in an organizational and political vacuum. As sources of incentive misalignment and contributors to the dispositions of power within the organization, disparate functional agendas and incentives, standardized organizational decision-making processes, and shared norms and values, all have an impact on the forecasting process and forecast accuracy (Bromiley, 1987). However, most of the academic literature only examines the individual and group unintentional biases that can affect forecasting ex situ (Armstrong, 2001a), with little research directed at managing the multi-objective and political dimensions of forecast generation and improvement in corporate settings (Bretschneider and Gorr, 1989; Deschamps, 2004).

Research on organizational factors and intentional sources of biases in forecasting has been done in the public sector where political agendas are explicit. This research suggests that directly confronting differences in goals and assumptions increases forecast accuracy. Bretschneider and Gorr (1987) and Bretschneider et al. (1989) found that a state's forecast accuracy improved if forecasts were produced independently by the legislature and executive, and then combined through a formal consensus procedure that exposed political positions and forecast assumptions. Deschamps 
(2004) found forecast accuracy to be improved by creating a neutral negotiation space and an independent political agency with dedicated forecasters to facilitate the learning of technical and consensus forecasting skills.

As different organizational functions have access to diverse commodities of power (e.g., sales has a unique access to current customer demand) we recognize that each group will have unique ways to influence the outcome of the forecasting process. The process through which groups with different interests reach accommodation ultimately rests on this disposition of power and it is referred to in the political science and management literatures as a political process (Crick, 1962; Dahl, 1970; Pfeffer and Salancik, 1974; Salancik and Pfeffer, 1977). In forecasting, a desirable outcome of a well-managed political contention would be a process that enables the known positive influences on forecast accuracy while weakening the negative influences on forecast accuracy. That is, a politically savvy process should take into consideration the commodities of power owned by the different functional areas and the impact that they might have on forecast accuracy, and explicitly manage the disposition of power to minimize negative influences on forecast accuracy.

\subsection{Abating Informational and Procedural Blind Spots}

Although functional goals and incentives can translate into intentional efforts to bias a forecast, other factors can affect forecasts in ways which managers might not be aware. Thus, we recognize unintentional, but systematic, sources of forecast error resulting from what we term blind spots, ignorance in specific areas which affect negatively an individual's or group's forecasts. Blind spots can be informational - related to an absence of otherwise feasibly collected information on which a forecast should be based — or procedural — related to the algorithms and tasks used to generate forecasts given the information available. This typology is an analytic one; the types are not always empirically distinct. Some informational blind spots could result from naiveté in forecasting methodology (procedural blind spot) that does not allow the forecaster to use the available 
information. Yet, while the two types may intermingle in an empirical setting, they tend to derive from different conditions and require different countermeasures.

We expect then that a forecasting process should try to manage the informational and procedural blind spots that may exist for the process. Some individual biases that have been shown to affect subjective forecasting include over-confidence, availability, anchor and adjustment, and optimism (Makridakis et al., 1998). Forecasters, even when provided with statistical forecasts as guides, have difficulty assigning less weight to their own forecasts (Lim and O'Connor, 1995). Cognitive information processing limitations and other biases related to the selection and use of information can also compromise the quality of plans. Gaeth and Shanteau (1984), for example, showed that irrelevant information aversely affected judgment, and Beach et al. (1986) showed that when the information provided is poor, forecasters might expend little effort to ensure that forecasts are accurate. Such individual biases can affect both the quality of the information collected and used to infer forecasts (informational blind spots), and the rules of inference themselves (procedural blind spots).

Research suggests process features and processing capabilities that might potentially mitigate the effect of individual biases. For example, combining forecasts with other judgmental or statistical forecasts tends to improve forecast accuracy (Lawrence et al., 1986). Goodwin and Wright (1993) summarize the research and empirical evidence that supports six strategies for improving judgmental forecasts: using decomposition, improving forecasters' technical knowledge, enhancing data presentation, mathematically correcting biases, providing feedback to forecasters to facilitate learning, and combining forecasts or using groups of forecasters.

Group forecasting is thought to contribute two important benefits to judgmental forecasting: (1) broad participation in the forecasting process maximizes group diversity, which reduces political bias and the tendency to cling to outmoded assumptions, assumptions that can contribute to both 
procedural and informational blind spots (Voorhees, 2000), and (2) the varied people in groups enrich the contextual information available to the process, reducing informational blind spots and thereby improving the accuracy of forecasts (Edmundson et al., 1988; Sanders and Ritzman, 1992). Some researchers maintain that such variety is even useful for projecting the expected accuracy of forecasts (Gaur et al., 2007; Hammond and Raman, 1995). Group dynamics can, however, have unwanted effects on the time to achieve consensus, the quality of consensus (whether true agreement or acquiescence), and thus, the quality of the forecasts. Kahn and Mentzer (1994), who found that a team approach led to greater satisfaction with the forecasting process, also reported mixed results regarding the benefits of group forecasting. Dysfunctional group dynamics reflect group characteristics such as the participants' personal dynamics, politics, information asymmetries, differing priorities, and varying information assimilation and processing capabilities.

Group processes can vary in terms of the degree of interaction afforded participants and the structure of the rules for interaction. The most popular structured, non-interacting, group forecasting approach is the Delphi method wherein a group's successive individual forecasts elicits anonymous feedback in the form of summary statistics (Rowe and Wright, 2001). Structured interacting groups, those with rules governing interaction, have not been found to perform significantly worse than groups that use the Delphi method (Rowe and Wright, 1999). However, Ang and O'Connor (1991) found that modified consensus (in which an individual's forecast was the basis for the group's discussion) outperformed forecasts based on group mean, consensus, and Nominal Group Technique (Delphi with some interaction).

\subsection{Conclusions from Review}

The above review suggests that while the current academic literature recognizes the need for an understanding of the organizational and political context in which the forecasting process takes place, the literature still lacks the operational and organizational frameworks for analyzing the 
generation of organizational forecasts. Our research aims to address this shortcoming by developing insights into managing the impact of the organizational and political dimensions of forecasting. The literature does lead us to expect a forecasting process that is attuned to the organizational and political context in which it operates, to be based on a group process, to combine information and forecasts from multiple sources, and to be deliberate about the way it allows different interests to affect forecast accuracy. We opted to explore this set of issues through a case study since the forecasting process has not been analyzed previously from this perspective, and our interest is to develop the constructs to understand its organizational and political context (Meredith, 1998). We consequently focus our analysis not on the forecast method (the specific technique used to arrive at a forecast), but on the forecasting process, that is, the way the organization has systematized information gathering, decision-making, and communication activities, and the organizational structure that supports that process.

\section{Research Methodology}

\subsection{Case Site}

The case site is a northern California-headquartered consumer electronics firm called Leitax (name has been disguised) that sold its products primarily through retailers such as Best Buy and Target and operated distribution centers (DCs) in North America, Europe, and the Far East. The Leitax product portfolio consisted of seven to nine models, each with multiple SKUs that were produced by contract-manufacturers with plants in Asia and Latin America. The product life across the models, which was contracting, ranged from nine to fifteen months, with high-end, feature-packed, products tending to have the shortest product lives.

The site was chosen because prior to the changes in the forecasting process, the situation was characterized by having shortcomings along the two dimensions described above. That is, the forecasting process was characterized by informational and procedural blind spots and was marred by intentional manipulation of information to advance functional agendas. The case site represents 
an exemplar for the study of the management of these dimensions, and constitutes a unique opportunity to test the integration of the two strands of theory that make explicit predictions about unintentional and intentional biases (Yin, 1984). The forecasting approach introduced was considered at least reasonably successful by many of the organizational participants and its forecasting accuracy, and accompanying improvements of operational indicators (e.g., inventory turns, obsolescence), corroborates this assessment. The issues and dynamics addressed by the implementation of the participatory forecasting process are issues that are not unique to Leitax, but characterize a significant number of organizations. Thus, the site provides a rich setting in which to seek to understand the dynamics involved in managing an organizational forecasting process and from which we expect to provoke theory useful for academics and practitioners alike. Our case study provides one reference for managing these organizational forecasts within an evolving business and operations strategy. As such, it does more to suggest potential relationships, dynamics, and solutions, than to definitively define or propose them.

\subsection{Research Design}

Insights were derived primarily from an intensive case study research (Eisenhardt, 1989; Yin, 1984) with the following protocol: the research was retrospective; the primary initiative studied, although evolving, was fully operational at the time the research was undertaken. Data were collected through 25 semi-structured, 45- to 90-minute interviews conducted with leaders, analysts, and participants from all functional areas involved in the forecasting process, as well as with heads of other divisions affected by the process. The interviews were supplemented with extensive reviews of archival data including internal and external memos and presentations, and direct observation of two planning and forecasting meetings. The intent of the interviews was to understand the interviewees' role in the forecasting process, their perception of the process, and to explore explicitly the unintentional biases due to blind spots as well as the political agendas of the different 
actors and functional areas. To assess the political elements of the forecasting process, we explicitly asked interviewees about their incentives and goals. We then triangulated their responses with answers from other actors and asked for explanations for observed behavior during the forecasting meetings. When appropriate, we asked interviewees about their own and other parties' sources of power, i.e., the commodity through which they obtained the ability to influence an outcome-e.g., formal authority, access to important information, external reputation (Checkland and Scholes, 1990). Most interviews were conducted in the organization's northern California facility, with some follow-up interviews done by telephone. Given the nature of the research, interviewees were not required to stay within the standard questions; interviewees perceived to be exploring fruitful avenues were permitted to continue in that direction. All interviews were recorded. Several participants were subsequently contacted and asked to elaborate on issues they had raised or to clarify comments. The data is summarized in the form of a detailed case study that relates the story of the initiative and current challenges (Watson and Oliva, 2005). Feedback was solicited from the participants, who were asked to review their quotations, and the case, for accuracy.

The analysis of the data was driven by three explicit goals: First, to understand the chronology of the implemented changes and the motivation behind those changes (this analysis led to the realization of mistrust across functional areas and the perceived biases that hampered the process). Second, to understand and to document the implemented forecasting process, the roles that different actors took within the process, and the agreed values and norms that regulated interactions within the forecasting group; and third, to assess how different elements of the process addressed or mitigated the individual or functional biases identified.

\section{Forecasting at Leitax}

The following description of the consensus forecasting process at Leitax was summarized from the interviews with the participants of the process. The description highlights the political dimension of 
the situation at Leitax by describing the differing priorities of the different functional groups and how power to influence the achievement of those priorities was expressed.

\subsection{Historical and Organizational Context}

Prior to 2001, demand planning at Leitax was ill-defined, with multiple private forecasts the norm. For new product introductions and mid-life product replenishment, the sales directors, (Leitax employed sales directors for three geographical regions- the Americas; Europe, the Middle East, and Africa; and Asia Pacific_ — and separate sales directors for Latin America and Canada) made initial forecasts that were informally distributed to the operations and finance groups, sometimes via discussions in hallways. These shared forecasts were intended to be used by the operations group as guides for communicating build or cancel requests to the supply chain. The finance group, in turn, would use these forecasts to guide financial planning and monitoring. These sales forecasts, however, were often mistrusted or second-guessed when they crossed into other functional areas. For example, with inventory shortages as its primary responsibility, the operations group would frequently generate its own forecasts to minimize the perceived exposure to inventory discrepancies, and marketing would do likewise when it anticipated that promotions might result in deviations from sales forecasts.

While the extent of bias in the sales forecast was never clearly determined; the mere perception that sales had an incentive to maintain high inventory positions in the channel was sufficient to compromise the credibility of its forecasts. Sales might well have intended to communicate accurate information to the other functions, but incentives to achieve higher sell-in rates tainted the objectivity of its forecasting, which occasioned the other functions' distrust and consequent generation of independent forecasts. Interviewees, furthermore, suspected executive forecasts to be biased by goal setting pressures, operational forecasts to be biased by inventory liability and utilization policies, and finance forecasts to be biased by market expectations and profitability 
thresholds. These biases stem from what are believed to be naturally occurring priorities of these functions.

Following two delayed product introductions that resulted in an inventory write-off of approximately 10\% of FY01-02 revenues, major changes were introduced during the fall of 2001 including the appointment of a new CEO and five new vice-presidents for product development, product management, marketing, sales, and operations. In April 2002, the newly hired director of planning and fulfillment launched a project with the goal of improving the velocity and accuracy of planning information throughout the supply chain.

Organizationally, management and ownership of the forecasting process fell to the newly created Demand Management Organization (DMO), which had responsibility for managing, synthesizing, challenging, and creating demand projections to pace Leitax's operations worldwide. The three analysts who comprised the group, which reported to the director of planning and fulfillment, were responsible not only for preparing statistical forecasts but also for supporting all the information and coordination requirements of the forecasting process.

By the summer of 2003, a stable planning and coordination system was in place and by the fall of 2003, Leitax had realized dramatic improvements in forecasting accuracy. Leitax defined forecast accuracy as one minus the ratio of the absolute deviation of sales from forecast to the forecast (FA=1-|sales-forecast//forecast). Three-month ahead sell-through (sell-in) forecast accuracy improved from 58\% (49\%) in the summer of 2002 to $88 \%(84 \%)$ by fall 2003 (see Figure 1). Sell-in forecasts refer to expected sales from Leitax's DCs into their resellers, and sell-through forecasts refer to expected sales from the resellers. Forecast accuracy through '05 was sustained at an average of $85 \%$ for sell-through. Better forecasts translated into significant operational improvements: Inventory turns increased to 26 in Q4 '03 from 12 the previous year, and average on hand inventory decreased from $\$ 55 \mathrm{M}$ to $\$ 23 \mathrm{M}$. Excess and obsolescence costs decreased from an average of $\$ 3 \mathrm{M}$ 
for fiscal years 2000-2002 to practically zero in fiscal year 2003. The different stages of the forecasting process are described in detail in the next section.

\subsection{Process Description}

By the fall of 2003, a group that included the sales directors and VPs of marketing, product strategy, finance, and product management, were consistently generating a monthly forecast. The process, depicted in Figure 2, begins with the creation of an information package, referred to as the business assumptions package, from which functional forecasts are created. These forecasts are combined and discussed at consensus forecasting meetings until there is a final forecast upon which there is agreement.

\section{Business Assumptions Package}

The starting point for the consensus forecasting process, the business assumptions package (BAP), contained price plans for each SKU, intelligence about market trends and competitors' products and marketing strategies, and other information of relevance to the industry. The product planning and strategy, marketing, and DMO groups guided assessments of the impact of the information on future business performance entered into the BAP (an Excel document with multiple tabs for different types of information and an accompanying PowerPoint presentation). These recommendations were carefully labeled as such and generally made in quite broad terms. The BAP generally reflected a one-year horizon, and was updated monthly and discussed and agreed upon by the forecasting group. The forecasting group generally tried not to exclude information deemed relevant from the BAP even when there were differences in opinion about the strength of the relevance. The general philosophy was that of an open exchange of information that at least one function considered relevant.

\section{Functional Forecasts}

Once the BAP was discussed, the information in it was used by three groups: product planning and strategy, sales, and the DMO, to elaborate functional forecasts at the family level, leaving the 
breakdown of that forecast into specific SKU demand to the sales and packing schedules. The three functional forecasts were made for sell-through sales and without any consideration to potential supply chain capacity constraints. Product planning and strategy (PPS), a three-person group that supported all aspects of product life cycle from launch to end-of-life, and assessed competitive products and effects of price changes on demand, prepared a top-down forecast of global expected demand. The PPS forecast reflected a worldwide estimate of product demand derived from product and region specific forecasts based on historical and current trends of market-share and the current portfolio of products being offered by Leitax and its competitors. The PPS group relied on external market research groups to spot current trends, and used appropriate history as precedent in assessing competitive situations and price effects.

The sales directors utilized a bottom-up approach to generate their forecast. Sales directors from all regions aggregated their own knowledge and that of their account managers about channel holdings, current sales, and expected promotions to develop a forecast based on information about what was happening in the distribution channel. The sales directors' bottom-up forecast was first stated as a sell-in forecast. Since incentives for the sales organization were based on commissions on sell-in, this was how account managers thought of the business. The sell-in forecast was then translated into a sell-through forecast that reflected the maximum level of channel inventory (inventory at downstream DC's and at resellers). The sales directors' bottom-up forecast, being based on orders and retail and distribution partner feedback, was instrumental in determining the first 13 weeks of the master production schedule.

The DMO group prepared, on the basis of statistical inferences from past sales, a third forecast of sell-through by region intended primarily to provide a reference point for the other two forecasts. Significant deviations from the statistical forecast would require that the other forecasting groups investigate and justify their assumptions. 
The three groups' forecasts were merged into a proposed consensus forecast using a formulaic approach devised by the DMO that gave more weight to the sales directors' forecast in the short term.

\section{Consensus Forecast Meetings}

The forecasting group met monthly to evaluate the three independent forecasts and the proposed consensus forecast. The intention was that all parties at the meeting would understand the assumptions that drove each forecast and agree to the consensus forecast based on their understanding of these assumptions and their implications. Discussion tended to focus on the nearest two quarters. In addition to some detail planning for new and existing products, the consensus forecast meetings were also a source of feedback on forecasting performance. In measuring performance, the DMO estimated the 13-week (the longest lead-time for a component in the supply chain) forecasting accuracy based on the formula that reflected the fractional forecast error ( $\mathrm{FA}=1$-|sales-forecast|/forecast).

\section{Finalizing Forecasts}

The agreed upon final consensus forecast $(\mathrm{FCF})$ was sent to the finance department for financial roll up. Finance combined the FCF with pricing and promotion information from the BAP to establish expected sales and profitability. Forecasted revenues were compared with the company's financial targets; if gaps were identified, an attempt was made to ensure that the sales department was not under-estimating market potential. If revisions made at this point did not result in satisfactory financial performance, the forecasting group would return to the business assumptions and, together with the marketing department, revise the pricing and promotion strategies to meet financial goals and analyst expectations. These gap-filling exercises, as they were called, usually occurred at the end of each quarter and could result in significant changes to forecasts. The approved FCF was released and used to generate the master production schedule.

Operations validation of the FCF was ongoing. The FCF was used to generate consistent and 
reliable production schedules for Leitax's contract manufacturers and distributors. Suppliers responded by improving the accuracy and opportunity of information flows regarding the status of the supply chain and their commitment to produce received orders. More reliable production schedules also prepared suppliers to meet future expected demand. Capacity issues were communicated and discussed in the consensus meetings and potential deviations from forecasted sales incorporated in the BAP.

\section{Analysis}

In this section we examine how the design elements of the implemented forecasting process addressed potential unintentional functional biases (i.e., informational and procedural blind spots), and resolved conflicts that emerge from misalignments of functional incentives. We first take a process perspective and analyze how each stage worked to minimize functional and collective blind spots. In the second subsection, we present an analysis of how the process managed the commodities of power to improve forecast accuracy. Table 1 summarizes the sources of intentional and unintentional biases addressed by each stage of the consensus forecasting process.

\subsection{Process Analysis}

Business Assumptions Package

The incorporation of diverse information sources is one of the main benefits reported for group forecasting (Edmundson et al., 1988; Sanders and Ritzman, 1992). The BAP document explicitly incorporated and assembled information in a common, sharable format that facilitated discussion by the functional groups. The sharing of information not only eliminated some inherent functional blind spots, but also provided a similar starting point for, and thereby improved the accuracy of, the individual functional forecasts (Fildes and Hastings, 1994). The guidance and recommendations provided by the functional groups' assessments of the impact of information in the BAP on potential demand represented an additional point of convergence for assimilating diverse information. The fact that the functions making these assessments were expected to have greater 
competencies for determining such assessments, helped to address potential procedural blind spots for the functions that used these assessments. The fact that these assessments and interpretations were explicitly labeled as such made equally explicit their potential for bias. Finally, the generation of the BAP in the monthly meetings served as a warm-up to the consensus forecasting meeting inasmuch as it required consensus about the planning assumptions.

\section{Functional Forecasts}

The functional forecasts that were eventually combined into the proposed consensus forecast were generated by the functional groups, each following a different methodological approach. Although the BAP was shared, each group interpreted the information it contained according to its own motivational or psychological biases. Moreover, there existed private information that had not been economical or feasible to include in, or that had been strategically withheld from, the BAP (e.g., actual customer intended orders, of which only sales was cognizant). The combination of the independently generated forecasts using even a simple average would yield a forecast that captured some of the unique and relevant information in, and thereby improved the accuracy of, the constituent forecasts (Lawrence et al., 1986). At Leitax, the functional forecasts were combined into the proposed consensus forecast using an algorithm more sophisticated that the simple average, based, as the literature recommends (Armstrong, 2001b), on the track record of the individual forecasts. By weighting the sales directors' forecast more heavily in the short-term and the PPS's forecast more heavily in the long-term, the DMO recognized each function's different level of intimacy with different temporal horizons, thereby reducing the potential impact of functional blind spots. Through this weighting, the DMO also explicitly managed each group's degree of influence on the forecasting horizon, which could have served as political appeasement.

\section{Consensus Forecasting Meetings}

The focus of the forecasting process on sell-through potentially yielded a clearer signal of market demand as sell-in numbers tended to be a distorted signal of demand; the sales force was known to 
have an incentive to influence sell-in in the short-term and different retailers had time-varying appetites for product inventory. Discussion in the monthly consensus forecasting meetings revolved mainly around objections to the proposed consensus forecast. In this context, the proposed consensus forecast provided an anchoring point that was progressively adjusted to arrive at the final consensus forecast (FCF). Anchoring on the proposed consensus forecast not only reduced the cognitive effort required of the forecasting team members, but also eliminated their psychological biases and reduced the functional biases that might still be present in the functional forecasts. There is ample evidence in the literature that an anchoring and adjustment heuristic improves the accuracy of a consensus approach to forecasting (Ang and O'Connor, 1991).

Discussion of objections to the proposed consensus forecast was intended to surface the private information or private interpretation of public information that motivated the objections. These discussions also served to reveal differences in the inference rules that functions used to generate forecasts. Differences might result from information that was not revealed in the BAP, from incomplete rules of inference (i.e., rules that do not consider all information), or from faulty rules of inference (i.e., rules that exhibited inconsistencies in logic). Faulty forecast assumptions were corrected and faulty rules of inference refined over time.

The consensus meetings were also a source of feedback to the members of the forecasting group on forecasting performance. The feedback rendered observable not only unique and relevant factors that affect the accuracy of the overall forecasting process, but, through the three independent functional forecasts, other factors such as functional or psychological biases. For example, in early 2004 the DMO presented evidence that sale's forecasts tended to over-estimate near- and underestimate long-term sales. Fed back to the functional areas, these assessments of the accuracy of their respective forecasts created awareness of potential blind spots. The functional forecasts' historical accuracy also served to guide decision-making under conditions that demanded precision such as 
allocation under constrained capacity or inventory.

The director of planning and fulfillment's selection of a measure of performance to guide these discussions is also worthy of note. Some considered this measure of accuracy, which compared forecasts to actual sales as if actual sales represented true demand, simplistic. Rather than a detailed, complex measure of forecast accuracy, he opted to use a metric that in its simplicity was effective only in providing a directional assessment of forecast quality (i.e., is forecast accuracy improving over time?). Tempering the pursuit of improvement of this accuracy metric, the director argued that more sophisticated metrics (e.g., considering requested backlog to estimate final demand) would be more uncertain, convey less information, and prevent garnering sufficient support to drive improvement of the forecasting process.

\section{Supporting Financial and Operational Planning}

Leitax's forecasting process, having the explicit goal of supporting financial and operational planning, allowed these functions to validate the agreed upon consensus forecast by transforming it into a revenue forecast and a master production schedule. Note, however, the manner in which exceptions to the forecast were treated: if the financial forecast was deemed unsatisfactory or the production schedule not executable because of unconsidered supply chain issues, a new marketing and distribution plan was developed and incorporated in the BAP. Also, note that this approach was facilitated by the process ignoring capacity constraints in estimating demand. It was common before the implementation of the forecasting process for forecasts to be affected by perceptions of present and future supply chain capacity, which resulted in a subtle form of self-fulfilling prophecy; even if manufacturing capacity became available, deflated forecasts would have positioned lower quantities of raw materials and components in the supply chain.

By reflecting financial goals and operational restrictions in the BAP and asking the forecasting group (and functional areas) to update their forecasts based on the new set of assumptions, instead of adjusting the final consensus forecast directly, Leitax embedded the forecasting process in the 
planning process. Reviewing the new marketing and product development plans reflected in the BAP, and validating it through the lenses of different departments via the functional and consensus forecast, essentially ensured that all of the functional areas involved in the process were re-aligned with the firm's needs and expectations. Separation of the forecasting and decision-making processes has been found to be crucial to forecast accuracy (Fildes and Hastings, 1994). We discuss the contributions of this process to cross-functional coordination and organizational alignment in a separate paper (Oliva and Watson, 2006).

\subsection{Political Analysis}

As shown in Table 1, certain components of the forecasting process dealt directly with the biases created by incentive misalignment. However, the implementation of the forecasting process was accompanied with significant structural additions, which we examine here via a political analysis.

As mentioned in the section 2, we expect the forecasting process to create a social and procedural context that enables, through the use of commodities of power, the positive influences on forecast accuracy, while weakening the influence of functional biases that might reduce the forecast accuracy. The most significant component of this context is the creation of the DMO. Politically, the DMO was an independent group with responsibility for managing the forecasting process.

The introduction of an additional group and its intrinsic political agenda might increase the complexity of the forecasting process and thereby reduce its predictability or complicate its control. However, the DMO, albeit neutral, was by no means impotent. Through the mandate to manage the forecasting process and being accountable for its accuracy, the DMO had the ability to determine the impact of different functions on forecast accuracy and to enforce procedural changes to mediate their influence. Specifically, related to biases due to incentive misalignment, because the DMO managed all exchanges of information associated with the process, it determined how other functions' power and influence would be expressed in the forecasts and could enforce the 
expression of this influence in production requests and inventory allocation decisions. The direct empowerment of the DMO group at Leitax resulted from its relationship with the planning function that made actual production requests and inventory allocations. The planning function, in turn, derived its power from the corporate mandate for a company turnaround. While the particular means of empowerment of the DMO group are not consequential - alternative sources of power could have been just as affective- the fact that DMO was empowered was crucial for the creation and the success of the forecasting process.

The empowerment of the DMO may seem antithetical to a consensual approach. In theory, the presence of a neutral body has been argued to be important for managing forecasting processes vulnerable to political influence (Deschamps, 2004), as a politically neutral actor is understood to have a limited desire to exercise power and is more easily deferred to for arbitration. In practice, an empowered entity such as the DMO needs to be careful to use this power to maintain the perception of neutrality. In particular, the perception of neutrality was reinforced by the DMO's mandate to manage the forecasting process (as opposed to actual forecasts), the simplicity and transparency of the information exchanges (basic Excel templates), and performance metrics (recall the director's argument for the simplest measure of forecast accuracy).

The forecasting process is itself an example of the empowerment of a positive influence on forecasting performance. The feasibility of the implemented forecasting process derived from the creation of the DMO and the director's ability to assure the attendance and participation of the VPs in the consensus forecasting meetings. While the forecasting process might have been initially successful because of this convening power, the process later became self-sustaining when it achieved credibility among the participants and the users of the final consensus. At that point in time, the principal source of power (ability to influence the forecast) became expertise and internal reputation as recognized by the forecasting group based on past forecasting performance. 
Interestingly, this historical performance also reinforced the need for a collaborative approach to forecasting as no function had distinguished itself as possessing the ability to manage the process single-handedly.

Nevertheless, since the forecasting approach accommodated some influence by functional groups, the DMO could be criticized for not eliminating fully opportunities for incentive misalignment. Functional groups represent stakeholders with information sets and goals relevant to the organization's viability, thus, it is important to listen to those interests. It is, however, virtually impossible to determine a priori whether the influence of any function will increase or decrease forecast accuracy. Furthermore, its own blind spots precluded the DMO from fully representing these stakeholders. Consequently, it is conceivably impossible to eliminate incentive misalignment entirely if stakeholder interests are to be represented in the process.

Summarizing, the DMO managed the above complicating factors in its development of the forecasting process by generating the proposed consensus forecast and having groups react to, or account for, major differences with it. The process implemented by the DMO shifted the conversation from functional groups pushing for their respective agendas, to justifying the sources of the forecasts and explicitly recognizing areas of expertise or dominant knowledge (e.g., sales in the short-term, PPS in the long term). The participatory process and credibility that accrued to the forecasting group consequent to improvements in forecast accuracy made the final consensus forecast more acceptable to the rest of the organization and increased its effectiveness in coordinating procurement, manufacturing, and sales (Hagdorn-van der Meijden et al., 1994).

\section{Emerging Challenges}

The deployment of a new system can introduce entirely new dynamics in terms of influence over forecasts and active biases. Here, we describe two missteps suffered in 2003 and relate performance feedback from participants in the consensus forecasting process and then explore the implications 
for the design of the process and the structure that supports it.

\subsection{Product Forecasting Missteps}

The first misstep occurred when product introduction and early sales were being planned for a new product broadly reviewed and praised in the press for its innovative features. Although the forecasting process succeeded in dampening to some degree the specialized press' enthusiasm, the product was nevertheless woefully over-forecasted and excess inventory resulted in a write-off of more than $1 \%$ of lifetime volume materials cost. The second misstep occurred when Leitax introduced a new product that was based on a highly successful model currently being sold to the professional market. Leitax considered the new product inferior in quality since it was cheaper to manufacture and targeted it at "prosumers," a marketing segment considered to be between the consumer and professional segments. Despite warnings from the DMO suggesting the possibility of cannibalization, the consensus forecast had the existing product continuing its impressive sales rate throughout the introduction of the new product. The larger-than-expected cannibalization resulted in an obsolescence write off for the existing product of $3 \%$ of lifetime volume materials cost.

These two missteps suggest a particular case of "groupthink" (Janis, 1972), whereby optimism, initially justified, withstands contradictory data or logic as functional (or individual) biases common to all parties tend to be reinforced. Since the forecasting process seeks agreement, when the input perspectives are similar but inaccurate, as in the case of the missteps described above, the process can potentially reinforce the inaccurate perceptions.

In response to these missteps, the DMO group considered changing the focus of the consensus meetings from the next two quarters towards the life-cycle quantity forecasts for product families and allowing the allocation to quarters to be more historically driven. This would serve to add another set of forecasts to the process to help improve accuracy. This focus on expected sales over the life of the product would also help mediate the intentional biases driven by natural interest in 
immediate returns that would surface when the two nearest quarters were instead the focus. The DMO group, however, had to be careful about how the changes were introduced so as to maintain its neutral stance and not create the perception of generating forecasts rather than the forecasting process.

\subsection{Interview Evaluations}

General feedback from interviewees reported lingering issues with process compliance. For instance, more frequently than the DMO expected, the process yielded a channel inventory level greater than the desired 7 to 8 weeks. This was explained by overly optimistic forecasts from sales and sales' over selling into the channel in response to its incentives. Some wondered about the appropriate effect of the finance group on the process. Sales, for example, complained that finance used the consensus meetings to push sales for higher revenues. Gap-filling exercises channeling feedback from finance back into the business assumptions, sometimes effected significant changes to forecasts that seemed inappropriate.

The inappropriate effects of sales and finance described above can be compared with the dynamics that existed before implementation to reveal emerging challenges associated with the forecasting process. For example, under DMO's inventory allocation policies, the only line of influence for sales is its forecasts — the process had eliminated the other sources of influence that sales had. Thus, sales would explicitly bias its forecasts in an attempt to swing regional sales in the preferred direction. For finance, the available lines of influence are the gap-filling exercises and the interaction within the consensus forecasting meetings. Given that the incentives and priorities of these functions had not changed, the use of lines of influence in this manner is not unexpected. However, it is not easy to predict exactly how these lines of influence will be used.

\subsection{Implications for Coordination System Design}

The consensus forecasting process occasioned lines of influence on forecasts to be used in ways that were not originally intended, and did not always dampen justifiable optimism regarding product 
performance. The latter dynamic can be characterized as a group bias whereby functional (individual) biases/beliefs common to all parties tend to be reinforced. Since the process seeks agreement, when the input perspectives are similar but inaccurate, as in the case of the missteps described above, the process can potentially reinforce the inaccurate perceptions.

Both dynamics illustrate how, in response to a particular set of processes, responsibilities, and structures - what we call a coordination system (Oliva and Watson, 2004) — new behavioral dynamics outside of those intended by the process might develop, introducing weaknesses (and conceivably strengths) not previously observed in the process. In principle, a coordinating system should be designed to account and compensate for individual and functional biases of supply chain partners. But coordination system design choices predispose individual partners to certain problem space, simplifications, and heuristics. Because the design of a coordinating system determines the complexity of each partner's role, it is also, in part, responsible for the biases exhibited by the partners. In other words, changes attendant on a process put in place to counter particular biases might unintentionally engender a different set of biases.

The recognition that a coordinating system both needs to account, and is in part responsible, for partners' biases, introduces a level of design complexity not currently acknowledged. Managers need to be aware of this possibility and monitor the process in order to identify unintended adjustments, recognizing that neither unintended behavioral adjustments nor their effects are easily predicted given the many process interactions that might be involved. This dual relationship between the coordination system and associated behavioral schema (see Figure 3), although commonly remarked in the organizational theory literature (e.g., Barley, 1986; Orlikowski, 1992), has not previously been examined in the forecasting or operations management literatures.

\section{Conclusion}

The purpose of case studies is not to argue for specific solutions, but rather to develop explanations 
(Yin 1984). By categorizing potential sources of functional biases into a typology—intentional, that is, driven by incentive misalignment and dispositions of power, and unintentional, that is, related to informational and procedural blind spots—we address a range of forecasting challenges that may not show up as specifically as they do at Leitax, but are similarly engendered. By a complete mapping of the steps of the forecasting process, its accompanying organizational structure and its role within the planning processes of the firm, we detail the relevant elements of an empirically observed phenomenon occurring within its contexts. By capturing the political motivations and exchanges and exploring how the deployed process and structure mitigated the existing biases, we assess the effectiveness of the process in a dimension that has largely been ignored by the forecasting literature. Finally, through the assessment of new sources of biases after the deployment of the coordination system, we identify the adaptive nature of the political game played by the actors.

Through the synthesis of our observations on these relevant elements of this coordinated forecasting system, previous findings from the forecasting literature, and credible deductions linking the coordination system to the mitigation of intentional and unintentional biases identified and the emergence of new ones, we provide sufficient evidence for the following propositions concerning the management of organizational forecasts (Meredith 1998):

Proposition I: Consensus forecasting, together with the supporting elements of information exchange and assumption elicitation, can prove a sufficient mechanism for constructively managing the influence of both biases on forecasts while being adequately responsive to managing a fast-paced supply chain.

Proposition II: The creation of an independent group responsible for managing the consensus forecasting process, an approach that we distinguish from generating forecasts directly, provides an effective way of managing the political conflict and informational and procedural shortcomings occasioned by organizational differentiation.

Proposition III: While a coordination system - the relevant processes, roles and responsibilities, and structure — can be designed to address existing individual and functional biases in the organization, the new coordination system will in turn generate new individual and functional biases. 
The empirical and theoretical grounding of our propositions suggest further implications for practitioners and researchers alike. The typology of functional biases into intentional and unintentional highlights managers' need to be aware that better and more integrated information may not be sufficient for a good forecast, and that attention must be paid as well to designing the process so that the social and political dimensions of the organization are effectively managed. Finally, new intentional and unintentional biases can emerge directly from newly implemented processes. This places a continuous responsibility on managers monitoring implemented systems for emerging biases and understanding the principles for dealing with different types of biases, to make changes to these systems to maintain operational and organizational gains. Generating forecasts may involve an ongoing process of iterative coordination system improvement. For researchers in operations management and forecasting methods, the process implemented by Leitax might be seen, at a basic level, as a "how to" for implementing in the organization many of the lessons from the research in forecasting and behavioral decision-making. More important, the case illustrates the organizational and behavioral context of forecasting, a context that, to our knowledge, had not been fully addressed. Given the role of forecasting in the operations management function, and as argued in the introduction, future research is needed to continue to build frameworks for managing forecasting along the organizational and political dimensions in operational settings. Such research should be primarily empirical, including both exploratory and theory building methodology that can draw heavily from the current forecasting literature, which has uncovered many potential benefits for forecasting methods ex situ.

\section{References}

Ang, S., M.J. O'Connor, 1991. The effect of group-interaction processes on performance in timeseries extrapolation. Int. J. Forecast. 7 (2), 141-149.

Antle, R., G.D. Eppen, 1985. Capital rationing and organizational slack in capital-budgeting. Management Sci. 31 (2), 163-174. 
Armstrong, J.S. (ed.), 2001a. Principles of Forecasting. Kluwer Academic Publishers, Boston.

Armstrong, J.S., 2001b. Combining forecasts. In: J.S. Armstrong (Ed), Principles of Forecasting. Kluwer Academic Publisher, Boston, pp. 417-439.

Barley, S., 1986. Technology as an occasion for structuring: Evidence from observations of CT scanners and the social order of radiology departments. Adm. Sci. Q. 31, 78-108.

Beach, L.R., V.E. Barnes, J.J.J. Christensen-Szalanski, 1986. Beyond heuristics and biases: A contingency model of judgmental forecasting. J. Forecast. 5, 143-157.

Bower, P., 2005. 12 most common threats to sales and operations planning process. J. Bus. Forecast. 24 (3), 4-14.

Bretschneider, S.I., W.L. Gorr, 1987. State and local government revenue forecasting. In: S. Makridakis, and S.C. Wheelwright (Eds), The Handbook of Forecasting: A Manager's Guide. Wiley, New York, pp. 118-134.

Bretschneider, S.I., W.L. Gorr, 1989. Forecasting as a science. Int. J. Forecast. 5 (3), 305-306.

Bretschneider, S.I., W.L. Gorr, G. Grizzle, E. Klay, 1989. Political and organizational influences on the accuracy of forecasting state government revenues. Int. J. Forecast. 5 (3), 307-319.

Bromiley, P., 1987. Do forecasts produced by organizations reflect anchoring and adjustment. J. Forecast. 6 (3), 201-210.

Cachon, G.P., M.A. Lariviere, 2001. Contracting to assure supply: How to share demand forecasts in a supply chain. Management Sci. 47 (5), 629-646.

Checkland, P.B., J. Scholes, 1990. Soft Systems Methodology in Action. Wiley, Chichester, UK.

Copeland, T., T. Koller, J. Murrin, 1994. Valuation: Measuring and Managing the Value of Companies, 2nd ed. Wiley, New York.

Crick, B., 1962. In Defence of Politics. Weidenfeld and Nicolson, London.

Crittenden, V.L., L.R. Gardiner, A. Stam, 1993. Reducing conflict between marketing and manufacturing. Ind. Market. Manag. 22 (4), 299-309.

Dahl, R.A., 1970. Modern Political Analysis, 2nd ed. Prentice Hall, Englewood Cliffs, NJ.

Deschamps, E., 2004. The impact of institutional change on forecast accuracy: A case study of budget forecasting in Washington State. Int. J. Forecast. 20 (4), 647-657.

Edmundson, R.H., M.J. Lawrence, M.J. O'Connor, 1988. The use of non-time series information in sales forecasting: A case study. J. Forecast. 7, 201-211.

Eisenhardt, K.M., 1989. Building theories from case study research. Acad. Manage. Rev. 14 (4), $532-550$. 
Fildes, R., R. Hastings, 1994. The organization and improvement of market forecasting. J. Oper. Res. Soc. 45 (1), 1-16.

Fisher, M.L., A. Raman, 1996. Reducing the cost of demand uncertainty through accurate response to early sales. Oper. Res. 44 (1), 87-99.

Fisher, M.L., J.H. Hammond, W.R. Obermeyer, A. Raman, 1994. Making supply meet demand in an uncertain world. Harvard Bus. Rev. 72 (3), 83-93.

Gaeth, G.J., J. Shanteau, 1984. Reducing the influence of irrelevant information on experienced decision makers. Organ. Behav. Hum. Perf. 33, 263-282.

Gaur, V., S. Kesavan, A. Raman, M.L. Fisher, 2007. Estimating demand uncertainty using judgmental forecast. Man. Serv. Oper. Manage. 9 (4), 480-491.

Goodwin, P., G. Wright, 1993. Improving judgmental time series forecasting: A review of guidance provided by research. Int. J. Forecast. 9 (2), 147-161.

Griffin, A., J.R. Hauser, 1992. Patterns of communication among marketing, engineering and manufacturing: A comparison between two new product teams. Management Sci. 38 (3), 360373.

Griffin, A., J.R. Hauser, 1996. Integrating R\&D and Marketing: A review and analysis of the literature. J. Prod. Innovat. 13 (1), 191-215.

Hagdorn-van der Meijden, L., J.A.E.E. van Nunen, A. Ramondt, 1994. Forecasting—bridging the gap between sales and manufacturing. Int. J. Prod. Econ. 37, 101-114.

Hamel, G., C.K. Prahalad, 1989. Strategic intent. Harvard Bus. Rev. 67 (3), 63-78.

Hammond, J.H., 1990. Quick response in the apparel Industry. Harvard Business School Note 690038. Harvard Business School, Boston.

Hammond, J.H., A. Raman, 1995. Sport Obermeyer Ltd. Harvard Business School Case 695-002. Harvard Business School, Boston.

Hanke, J.E., A.G. Reitsch, 1995. Business Forecasting, 5th ed. Prentice Hall, Englewood Cliffs, NJ.

Hughes, M.S., 2001. Forecasting practice: Organizational issues. J. Oper. Res. Soc. 52 (2), 143-149.

Janis, I.L., 1972. Victims of Groupthink. Houghton Mifflin, Boston.

Kahn, K.B., J.T. Mentzer, 1994. The impact of team-based forecasting. J. Bus. Forecast. 13 (2), 1821.

Keating, E.K., R. Oliva, N. Repenning, S.F. Rockart, J.D. Sterman, 1999. Overcoming the improvement paradox. Eur. Mgmt. J. 17 (2), 120-134.

Lapide, L., 2005. An S\&OP maturity model. J. Bus. Forecast. 24 (3), 15-20. 
Lawrence, M.J., R.H. Edmundson, M.J. O'Connor, 1986. The accuracy of combining judgmental and statistical forecasts. Management Sci. 32 (12), 1521-1532.

Lim, J.S., M.J. O'Connor, 1995. Judgmental adjustment of initial forecasts: Its effectiveness and biases. J. Behav. Decis. Making 8, 149-168.

Mahmoud, E., R. DeRoeck, R. Brown, G. Rice, 1992. Bridging the gap between theory and practice in forecasting. Int. J. Forecast. 8 (2), 251-267.

Makridakis, S., S.C. Wheelwright, R.J. Hyndman, 1998. Forecasting: Methods and Applications, 3rd ed. Wiley, New York.

Mentzer, J.T., C.C. Bienstock, 1998. Sales Forecasting Management. Sage, Thousand Oaks, CA.

Meredith, J., 1998. Building operations management theory through case and field research. J. Oper. Manag. 16, 441-454.

Oliva, R., 2001. Tradeoffs in responses to work pressure in the service industry. California Management Review 43 (4), 26-43.

Oliva, R., J.D. Sterman, 2001. Cutting corners and working overtime: Quality erosion in the service industry. Management Sci. 47 (7), 894-914.

Oliva, R., N. Watson. 2004. What drives supply chain behavior? Harvard Bus. Sch., June 7, 2004. Available from: http://hbswk.hbs.edu/item.jhtml?id=4170\&t=bizhistory.

Oliva, R., N. Watson, 2006. Cross functional alignment in supply chain planning: A case study of sales \& operations planning. Working Paper 07-001. Harvard Business School, Boston.

Orlikowski, W., 1992. The duality of technology: Rethinking the concept of technology in organizations. Organ. Sci. 3 (3), 398-427.

Pfeffer, J., G.R. Salancik, 1974. Organizational decision making as a political process: The case of a university budget. Adm. Sci. Q. 19 (2), 135-151.

Rowe, G., G. Wright, 1999. The Delphi technique as a forecasting tool: Issues and analysis. Int. J. Forecast. 12 (1), 73-92.

Rowe, G., G. Wright, 2001. Expert opinions in forecasting: The role of the Delphi technique. In: J.S. Armstrong (Ed), Principles of Forecasting. Kluwer Academic Publishers, Norwell, MA, pp. 125-144.

Salancik, G.R., J. Pfeffer, 1977. Who gets power - and how they hold on to it: A strategiccontingency model of power. Org. Dyn. 5 (3), 3-21.

Sanders, N.R., L.P. Ritzman, 1992. Accuracy of judgmental forecasts: A comparison. Omega 20, 353-364.

Sanders, N.R., K.B. Manrodt, 1994. Forecasting practices in U.S. corporations: Survey results. Interfaces 24, 91-100. 
Sanders, N.R., L.P. Ritzman, 2001. Judgmental adjustment of statistical forecasts. In: J.S.

Armstrong (Ed), Principles of Forecasting. Kluwer Academic Publishers, Boston, pp. 405-416.

Shapiro, B.P., 1977. Can marketing and manufacturing coexist? Harvard Bus. Rev. 55 (5), 104-114.

Stein, J.C., 1997. Internal capital markets and the competition for corporate resources. Journal of Finance 52 (1), 111-133.

Terwiesch, C., Z.J. Ren, T.H. Ho, M.A. Cohen, 2005. An empirical analysis of forecast sharing in the semiconductor equipment supply chain. Management Sci. 51 (2), 208-220.

Voorhees, W.R., 2000. The impact of political, institutional, methodological, and economic factors on forecast error. PhD dissertation, Indiana University.

Watson, M.C., 1996. Forecasting in the Scottish electronics industry. Int. J. Forecast. 12 (3), 361371.

Watson, N., R. Oliva, 2005. Leitax (A). Harvard Business School Case 606-002. Harvard Business School, Boston.

Wheelwright, S.C., K.B. Clark, 1992. Revolutionizing Product Development. Wiley, New York.

Yin, R., 1984. Case Study Research. Sage, Beverly Hills, CA.

Figure 1. Forecast Accuracy Performance ${ }^{\dagger}$

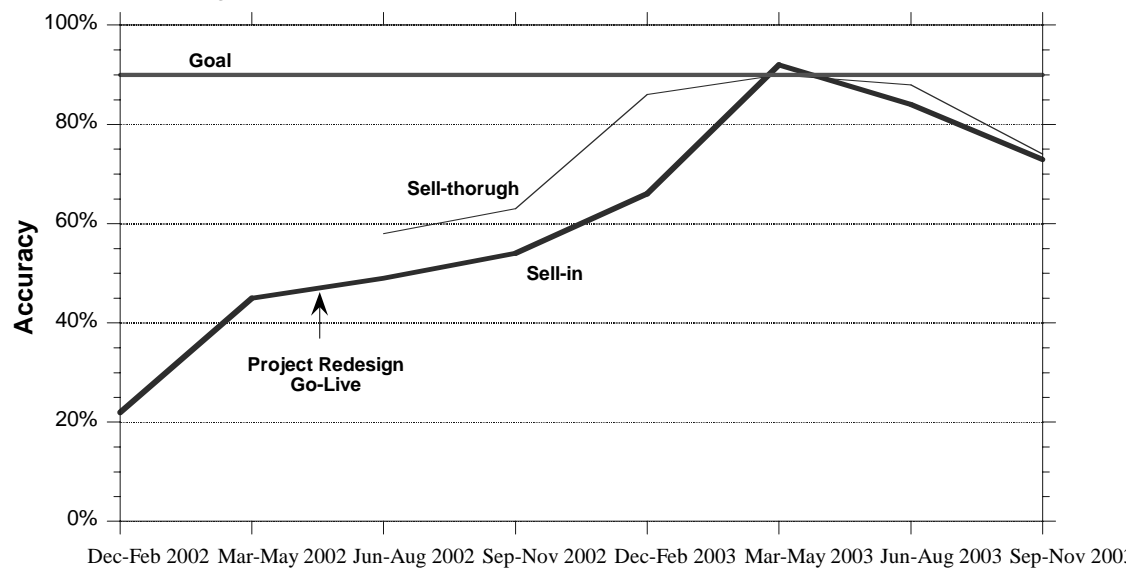

$\dagger$ The dip forecasting performance in Sept-Nov 2003 was as a result of a relocation of a distribution center. 
Figure 2. Consensus Forecasting Process

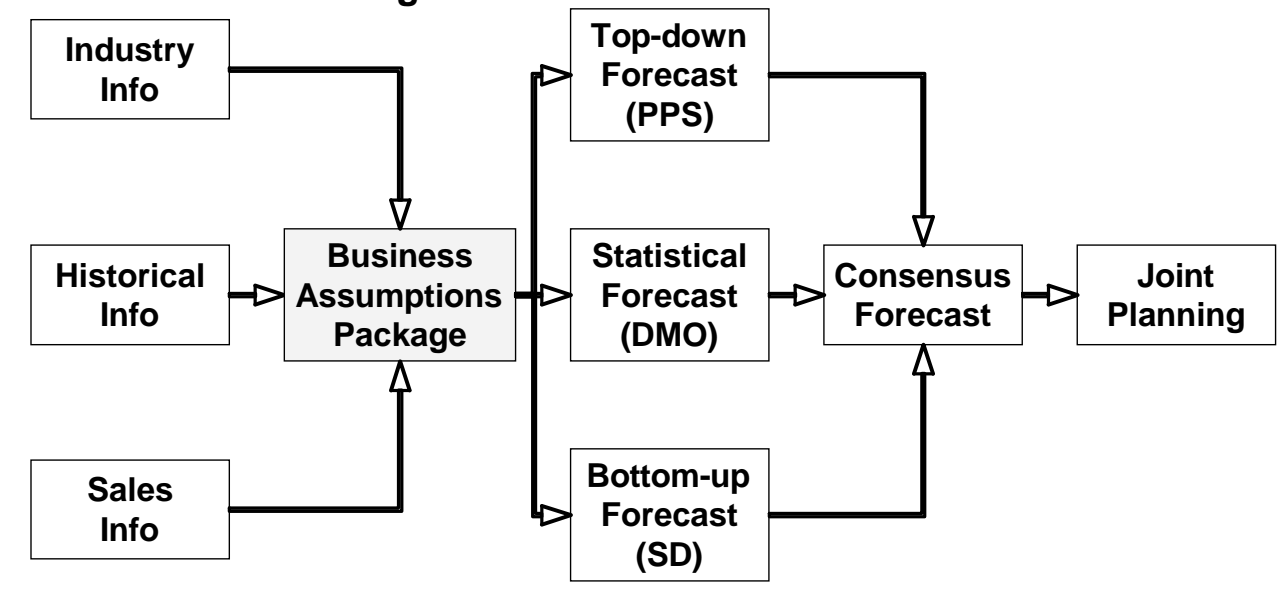

Figure 3. Dual Relationship between Coordination System and Behavioral Dynamics influence the design

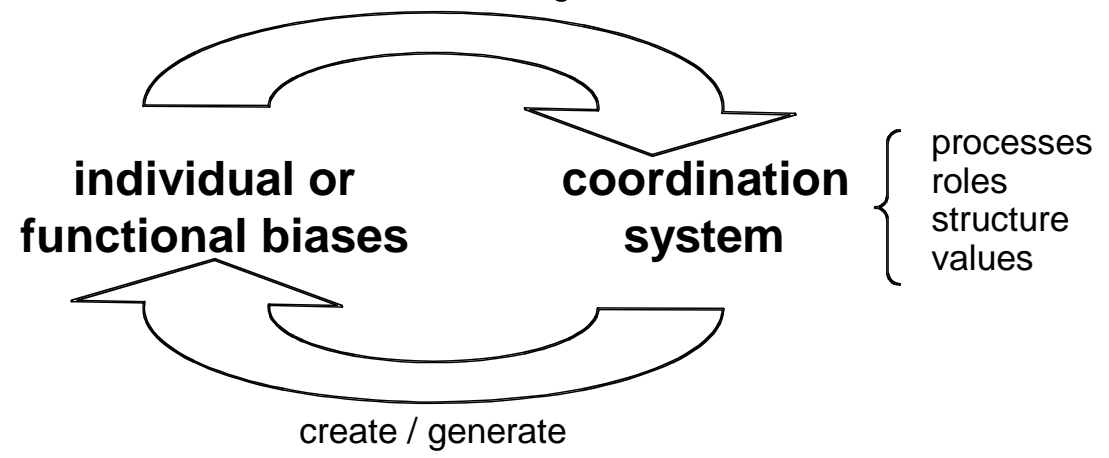

Table 1: Process Steps and Biases Mitigated

\section{Consensus Forecasting Process}

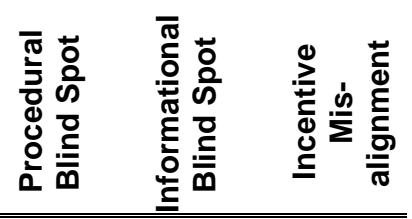

Business Assumptions Package

Multiple sources

Multiple interpretations

Interpretation source explicitly labeled

Functional forecasts

Private info not in BAP

Functional interpretation of assumptions

Aggregate forecasts at family level

Ignoring planning expectations supply chain constraints

Proposed Consensus Forecast

Weighted average of functional forecasts

Weights in terms of past proven performance

Initial anchoring for consensus process

Final consensus meeting

Resolution of diverging forecast

Uncover private information used in functional forecasts

Uncover private interpretation of public information

Forecast Review

Financial and Operational

$\mathrm{BAP}$ revision 